Please do not remove this page

RMIT

UNIVERSITY

\title{
Compacted nanosilica-talic/calcium carbonate polyacrylate composites prepared using accelerated sedimentation
}

Daud, Norlinda; Shanks, Robert; Kong, Ing

https://researchrepository.rmit.edu.au/esploro/outputs/9921858639901341/filesAndLinks?institution=61RMIT_INST\&index=null

Daud, N., Shanks, R., \& Kong, I. (2012). Compacted nanosilica-talic/calcium carbonate polyacrylate composites prepared using accelerated sedimentation. World Journal of Engineering, 9(5), 385-389. https://doi.org/10.1260/1708-5284.9.5.385

Published Version: https://doi.org/10.1260/1708-5284.9.5.385

Repository homepage: https://researchrepository.rmit.edu.au

(c) 2012 Multi-Science Publishing Co. Ltd

Downloaded On 2023/04/26 21:17:25 +1000 
Thank you for downloading this document from the RMIT Research Repository.

The RMIT Research Repository is an open access database showcasing the research outputs of RMIT University researchers.

RMIT Research Repository: http://researchbank.rmit.edu.au/

\section{Citation:}

Daud, N, Shanks, R and Kong, I 2012, 'Compacted nanosilica-talic/calcium carbonate polyacrylate composites prepared using accelerated sedimentation', World Journal of Engineering, vol. 9, no. 5, pp. 385-389.

See this record in the RMIT Research Repository at:

http://researchbank.rmit.edu.au/view/rmit:17702

Version: Published Version

Copyright Statement: (c) 2012 Multi-Science Publishing Co. Ltd

Link to Published Version:

http://dx.doi.org/10.1260/1708-5284.9.5.385 


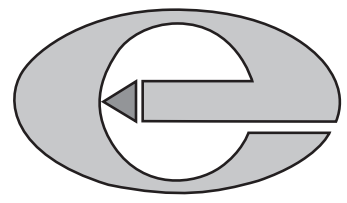

\title{
Compacted nanosilica-talc /calcium carbonate polyacrylate composites prepared using accelerated sedimentation
}

\author{
Norlinda Daud ${ }^{1,2}$, Robert A. Shanks ${ }^{1}$ and Ing Kong1,* \\ ${ }^{1}$ School of Applied Sciences, RMIT University Box 2476 GPO, Melbourne, VIC 3001, \\ Australia \\ ${ }^{2}$ Department of Chemistry, Faculty of Science and Mathematics, UPSI, 35900 Tg Malim, \\ Perak, Malaysia \\ *E-mail:ing.kong@rmit.edu.au
}

\begin{abstract}
(Received 17 November 2011; accepted 12 August 2012)

The effectiveness of centrifugation as the compacting method in preparing high filler composites has been investigated. Different size and shape of fillers were used to ensure efficient filler space filling. In situ polymerization of bisphenol-A ethoxy diacrylate after centrifugating produced biomimetic composites with $74-86 \%$ filler content. The filler space was efficiently filled by using a combination of nano and microsize fillers, especially in the nanosilica- $\mathrm{CaCO}_{3}$ composite. The morphology of the composites indicates that the fillers were well dispersed and embedded in the polymer matrix. The etched surface of the nanosilica-talc composite reveals that the combination of talc and nanosilica formed a biomimetic composite that displayed an ordered brick-and-mortar nacre-like structure. The wide-angle X-ray diffraction patterns indicate the crystal structure of $\mathrm{CaCO}_{3}$ and talc were maintained in the composite.
\end{abstract}

Key words: Centrifugation; Composite, Nanosilica, Accelerated sedimentation

\section{Introduction}

Biomimetic approaches to materials design have rapidly grown as has the potential to be explored and expanded scientifically and technologically. The term biomimetic is used to describe engineering design that mimics or imitates nature. Biomimetic materials are those where the component materials, technique of preparation or the microstructure are based upon naturally occurring materials.
High performance natural composites, such as nacre, demonstrate unparalleled combination of strength, stiffness and toughness, which are attributed to their intricate architectures. The excellent mechanical properties of nacre originate from its unique microstructure consisting of $95 \% \cdot \mathrm{w} / \mathrm{w}$ aragonite $\left(\mathrm{CaCO}_{3}\right)$ platelets and interfacial organic phase (Tushtev et al., 2008). The mineral platelets are arranged layer-by-layer separated by thin layers of biopolymer in a highly order brick-and-mortar

$\overline{\text { ISSN: } 1708-5284}$ 
structure. Artificial nacre-like layered organicinorganic composites have been prepared by several techniques such as biomineralization, layer-by-layer deposition, hot-press assisted slip casting (HASC) and roll compaction (Luz and Mano, 2010; Chen et al., 2008). Platelet fillers, for instance clay and talc are often chosen because they consist of crystal sheets of similar dimension as aragonite tablets.

Fabrication of high volume fraction mineral composites usually results in a non-uniform reinforcement distribution and porosity in the matrix. The addition of nanoparticles to composites generally improves their strength, modulus, toughness, heat resistance and dimensional stability. However, dispersion of the nanoparticles can be problematic due to their tendency to remain as aggregates or agglomerate, resulting in none of the anticipated enhancement in mechanical properties (Oberdisse, 2006).

The aim is to prepare and characterise, nanoscopic silica and micro-size $\mathrm{CaCO}_{3}$ and talc that are dispersed by ultrasonication. The filled prepolymer was very viscous, however centrifuging the dispersion, including the initiator, maximized the filler concentration.

\section{Experimental study}

\subsection{Materials}

Bisphenol-A ethoxy diacrylate (Ebecryl 150 from UCB Chemicals) was used as received. The amorphous fumed silica Aerosil 300 (Degussa, Germany) used in this work has a silica content of $>99.8 \% \cdot \mathrm{w} / \mathrm{w}$ and average primary particle size of 7 nm. Calcium carbonate, $\mathrm{CaCO}_{3}$ (Omyacarb) with an average particle size of $1.7 \mu \mathrm{m}$ was obtained from OMYA (Australia). Talc (T63A) was supplied by Orica Chemicals (Australia). All fillers were dried in an oven prior to use. Benzoyl peroxide and toluene were used as received from Merck, Germany.

\subsection{Composites preparation}

A nanosilica $(1 \% \cdot \mathrm{w} / \mathrm{w})$ was mixed in the monomer resin using impeller blade mechanical stirrer at $300 \mathrm{rpm}$ for $15 \mathrm{~min}$, followed by dispersion using ultrasonication for $15 \mathrm{~min} . \mathrm{CaCO}_{3}$ or talc $(24 \% \cdot \mathrm{w} / \mathrm{w})$ was then added and the dispersion was stirred for $15 \mathrm{~min}$ at $300 \mathrm{rpm}$ with ultrasonication for $15 \mathrm{~min}$. The suspension was degassed in vacuum until entrapped bubbles were removed completely. An initiator, benzoyl peroxide, $(1 \% \cdot \mathrm{w} / \mathrm{w})$, was dissolved in toluene and mixed at $100 \mathrm{rpm}$ for $2 \mathrm{~min}$. Immediately after mixing, the mixture was centrifuged at 10,000 rpm for $15 \mathrm{~min}$. The dispersion was cured by slowly heating to $90{ }^{\circ} \mathrm{C}$ for $6 \mathrm{~h}$ in a vacuum oven. The cured composite was removed from the centrifuge tube and cut using a diamond saw to form test specimens from the lower part of the cured resin. The upper fraction contained less filler since the filler had been compacted at the bottom of the tube during centrifuging.

\subsection{Characterization}

The thermal decomposition temperature was determined by thermogravimetry (TGA) using Perkin-Elmer Pyris 1 thermogravimetric analyzer. Samples of about $3.0 \mathrm{mg}$ were heated from 50 to $850{ }^{\circ} \mathrm{C}$ at a heating rate of $10 \mathrm{~K} \cdot \mathrm{min}^{-1}$. The purging gas (flow rate: $20 \mathrm{~mL} \cdot \mathrm{min}^{-1}$ ) was nitrogen from $50-700{ }^{\circ} \mathrm{C}$, then it was changed to air at $700{ }^{\circ} \mathrm{C}$.

The surface morphology of the fractured and etched composites was examined under a scanning electron microscope (SEM), specifically a FEI Nova NanoSEM (2007). A fractured sample was prepared by submerging it in liquid nitrogen for $1 \mathrm{~min}$ and then breaking it transversely with a rapid impact. For the etched sample, the cross-sections of the composites were cut, polished and then etched in a solvent mixture of $8 \mathrm{~mol} \cdot \mathrm{L}^{-1} \mathrm{NaOH}$ and methanol (3:2 volume ratio) and stirred for $2 \mathrm{~h}$. All samples were gold-coated prior to scanning.

Wide-angle X-ray diffraction (WAXD) patterns were recorded with a Bruker D8 Advance $\mathrm{X}$-ray diffractometer with $\mathrm{Cu} K \alpha 1$ radiation $(\lambda=$ $1.541 \AA$ ) in the $2 \theta$ range from $5^{\circ}$ to $60^{\circ}$, in steps of $0.02^{\circ}$.

\section{Results and discussion}

The composites were prepared by in situ polymerization, in which the monomer was polymerized in the presence of different filler combinations. Given the preparation route, the final filler composition in the prepared composites had to be verified by TGA (Figure 1). The degradation of the polymer occurred in two stages. In the first stage, at temperatures between 50 to $700{ }^{\circ} \mathrm{C}$, the weight loss of polymer $(95.9 \%)$ is attributed to the evaporation of moisture and organic solvent, volatilization of low molecular weight fragments and cleavage of the main chain accompanied by the combustion of the cleaved 


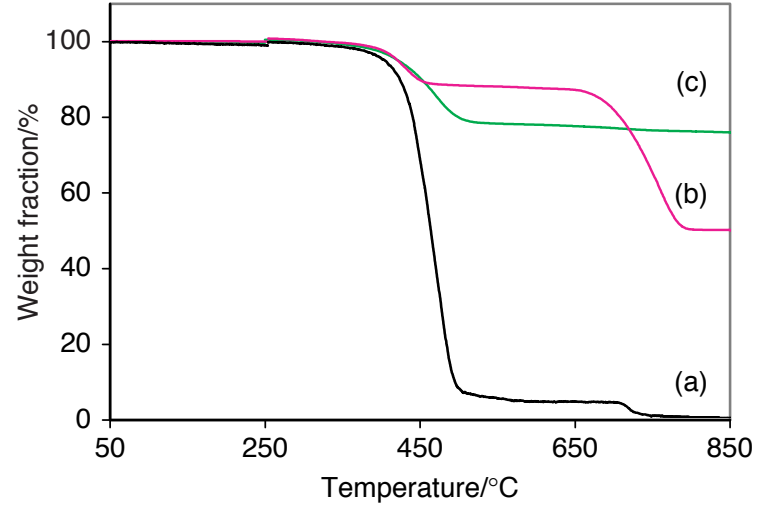

Fig. 1. TGA curve of (a) polymer, (b) nanosilica- $\mathrm{CaCO}_{3}$ composite and (c) nanosilica-talc composite.

products. The second decomposition $(4.1 \%)$ at temperature $>700{ }^{\circ} \mathrm{C}$ is ascribed to the further combustion or carbonization of organic compound when air was introduced at $700{ }^{\circ} \mathrm{C}$. No residue remained at $850^{\circ} \mathrm{C}$.

Similarly, nanosilica- $\mathrm{CaCO}_{3}$ composite decomposed in a two-stage process. The first stage of weight loss in the composite $(13.6 \%)$ at 50 to $650{ }^{\circ} \mathrm{C}$ is attributed to the degradation of the polymer matrix and the second weight loss (37.0\%) is mainly due to the loss of $\mathrm{CO}_{2}$ from the $\mathrm{CaCO}_{3}$ filler. The residue remaining at $850{ }^{\circ} \mathrm{C}$ mainly contained $\mathrm{CaO}$ and silica. Hence, the first weight loss was used to determine the weight fraction of filler in the composites.

The nanosilica-talc composite decomposed in a one-stage process. The decomposition is attributed to the degradation of the polymer matrix. The residue remaining at $850{ }^{\circ} \mathrm{C}(74.4 \%)$ contains talc and nanosilica and was used to determine the weight fraction of fillers in the composite. The weight fraction of fillers in nanosilica-talc and nanosilica- $\mathrm{CaCO}_{3}$ composites are $74.4 \%$ and $86.4 \%$ respectively.

Thermal stability of the cured resin and its composites were measured as the decomposition at temperature of $10 \%$ weight loss $\left(\mathrm{T}_{\mathrm{d}, 10 \%}\right)$. The $\mathrm{T}_{\mathrm{d}}, 10 \%$ for polymer, nanosilica- $\mathrm{CaCO}_{3}$ and nanosilica-talc composites are $418{ }^{\circ} \mathrm{C}, 443{ }^{\circ} \mathrm{C}$ and $448{ }^{\circ} \mathrm{C}$ respectively. The high $\mathrm{T}_{\mathrm{d}, 10 \%}$ observed for the composites is considered to be related to the tortuous path of degradation products, which is strongly related to the distribution of filler particles in the resin. In addition, this increase in the thermal stability could be attributed to the high thermal stability of the fillers and the interaction between the fillers and the polymer matrix. The fillers were considered to be acting as a thermal barrier, thereby protecting the polymer from degradation. The effective barrier action of the talc layers further enhances the thermal stability of the composites.

The morphology of the nanosilica- $\mathrm{CaCO}_{3}$ and nanosilica-talc composites are shown in Figure 2

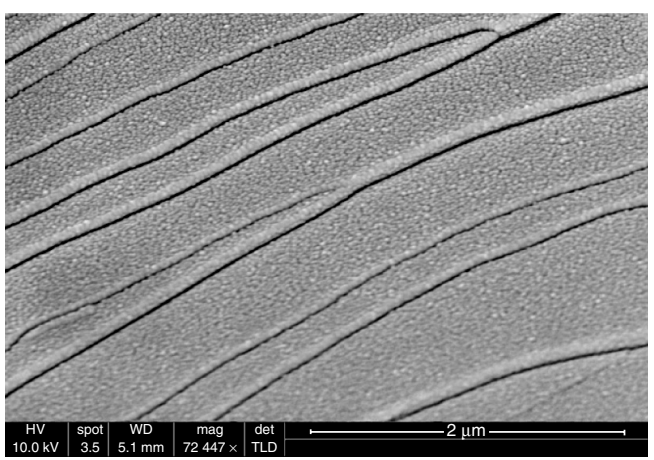

(a) Fractured surface

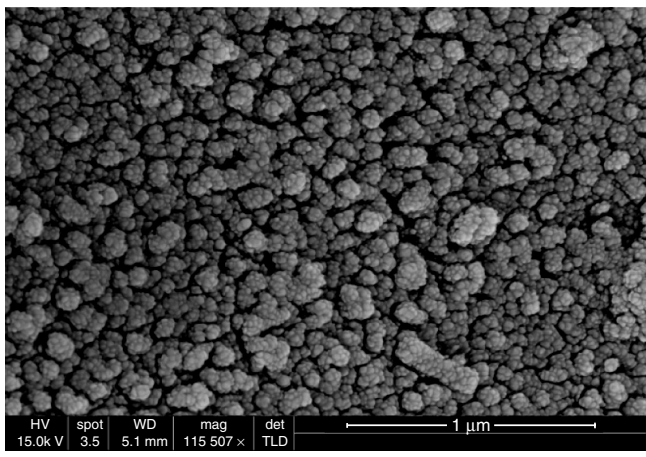

(b) Etched surface

Fig. 2. SEM image of the nanosilica-CaCO 3 composite.

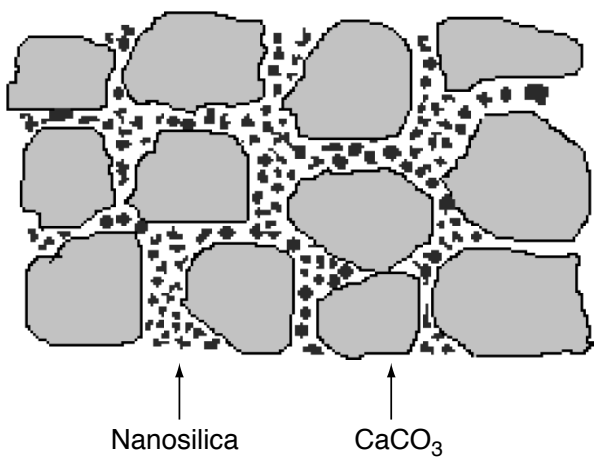

Fig. 3. Schematic drawing of nanosilica and $\mathrm{CaCO}_{3}$ dispersion in polymer matrix. 


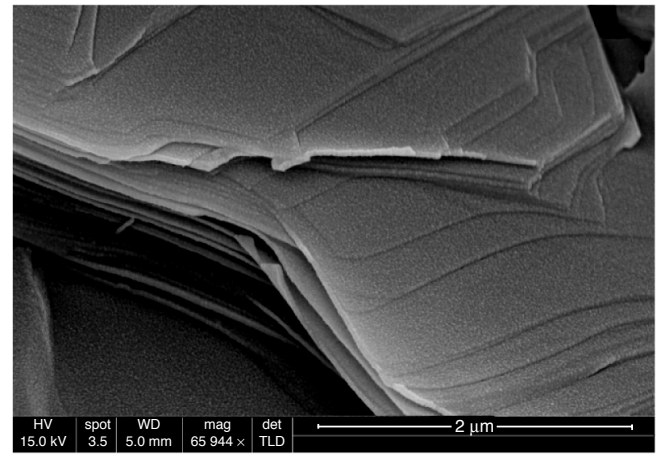

(a) Fractured surface.

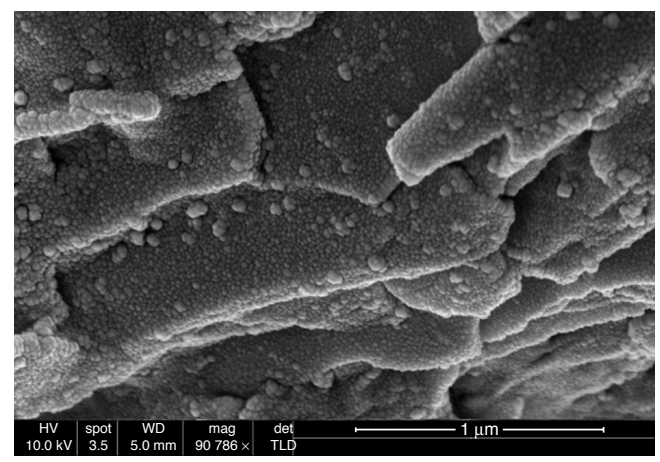

(b) Etched surface.

Fig. 4. SEM image of the nanosilica-talc composite.

and Figure 4, respectively. The SEM micrograph on Figure 2(a) confirms uniform distribution of the nanosilica and $\mathrm{CaCO}_{3}$ particles in the composite. The surface fracture of the nanosilica- $\mathrm{CaCO}_{3}$ composite shows that the fillers were well dispersed and embedded in the polymer matrix. The etched surface of the composite (Figure 2(b)) reveals small pores scattered evenly indicating that the composite was effectively compacted. The nanosilica is expected to fill the empty space between the micro-size filler particles as illustrated in Figure 3. Judging from the surface morphology, sonication led to a good dispersion of fillers in polymer matrix.

The SEM micrographs in Figure 4 reveal the distribution and orientation of talc platelets in the polyacrylate composite. Interestingly, the flakelike talc particles were dispersed and oriented in planes rather than randomly. The etched surface of the composite exhibits a layered structure, analogous to the nacre brick-and-mortar structure as illustrated in Figure 5.

The results confirm that the talc platelets were preferentially aligned in the centrifugal deposition process, hence efficiently compacting the composite. This finding is in agreement with another study that discovered the automatic alignment of clay platelets under centrifugal force (Chen et al., 2008). The centrifugation technique is similar to natural deposition of mineral in natural composites, except that instead of gravity, centripetal force was used to accelerate the sedimentation process.

Figure 6 shows the wide-angle X-ray diffraction (WAXD) patterns of the polymer, $\mathrm{CaCO}_{3}$ and nanosilica- $\mathrm{CaCO}_{3}$ composite. A large halo obtained in polymer pattern at around $2 \theta=20^{\circ}$ indicates the amorphous state of the cured resin. The relatively high intensity of the Bragg reflections is presented at the $(104)$ plane $\left(2 \theta=29.5^{\circ}\right)$ for $\mathrm{CaCO}_{3}$ and nanosilica- $\mathrm{CaCO}_{3}$ composites, which indicates that the $\mathrm{CaCO}_{3}$ is in the calcite form. The position of the peaks in the composite did not change, indicating the structure of the $\mathrm{CaCO}_{3}$ crystal was maintained in the composite. Similarly, the structure of the talc crystal in the composite did not change (Figure 7).

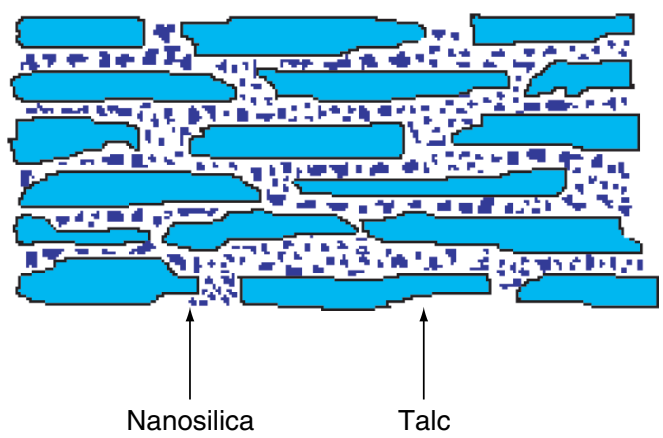

Fig. 5. Schematic drawing of ordered layered of nanosilica-talc composite.

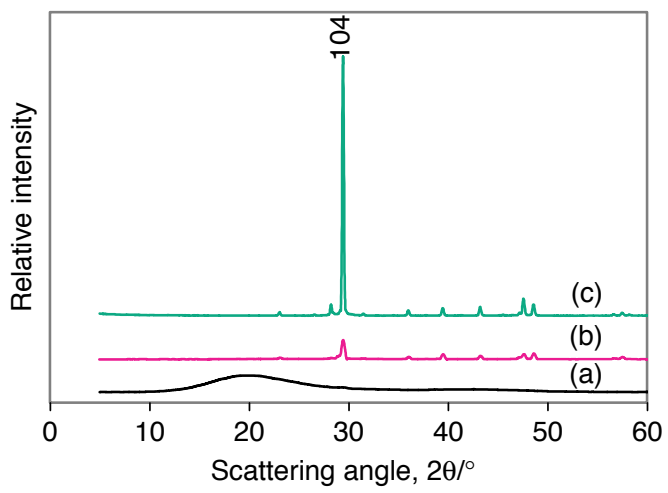

Fig. 6. Wide-angle X-ray diffraction (WAXD) pattern of (a) polymer, (b) nanosilica-CaCO 3 composite and (c) $\mathrm{CaCO}_{3}$. 


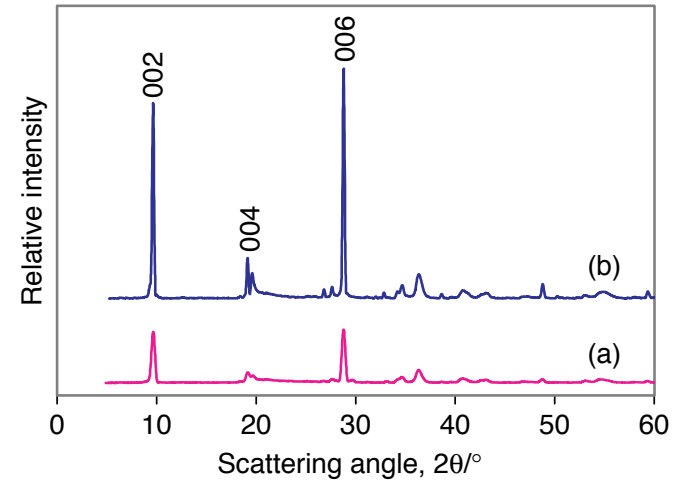

Fig. 7. Wide-angle X-ray diffraction (WAXD) pattern of (a) nanosilica-talc composite and (b) talc.

\section{Conclusions}

Centrifugation was applied to the fabrication of nanosilica-talc and nanosilica- $\mathrm{CaCO}_{3}$ nanocomposites as a compacting method. The filler space was efficiently filled by using a combination of nano- and micro-size fillers, especially in the nanosilica- $\mathrm{CaCO}_{3}$ composite. Centrifugation did not form layer-by-layer structure. However due to the talc platelet crystals, the nanosilica-talc composite displayed an ordered brickand-mortar nacre-like structure. The wide-angle $\mathrm{X}$-ray diffraction pattern of nanosilica- $\mathrm{CaCO}_{3}$ and nanosilica-talc composites confirmed that the structure of talc and $\mathrm{CaCO}_{3}$ crystals were maintained in the composite.

\section{References}

Chen R., Wang C., Huang Y. and Le Huirong, 2008. An accelerated biomimetic process for artificial nacre with ordered-nanostructure. Mater. Sci Eng., C 28, 218-222.

Luz G.M. and Mano J.F. 2010. Mineralized structures in nature: examples and inspirations for the design of new composite materials and biomaterials. Comp. Sci.Tech., 70: 1777-1788.

Oberdisse J., 2006. Aggregation of colloidal nanoparticles in polymer matrices. Soft Matter 2, 29-36.

Tushtev K., Murck M. and Grathwohl G., 2008. .On the nature of the stiffness of nacre. Mater. Sci. Eng., C 28, 1164-1172. 
